\title{
El encadenamiento de los diálogos a través de los sentimientos: clave de lectura en la Homilía VIII de Germán de Constantinopla
}

Elisa Ferrer

Universidad Nacional de Córdoba, Argentina elisaferrer@ffyh.unc.edu.ar

\begin{abstract}
Resumen
Este artículo espera demostrar que los topoi de la pena y de la alegría sostienen la estructura narrativa de la Homilía VIII de Germán de Constantinopla. Junto a la alternancia de discursos que se intercalan en el relato principal se reconoce también una alternancia en las reacciones que ellos suscitan. Se revisará la organización de esos parlamentos en su relación con el hilo principal, y se analizará la respuesta producida por cada uno de ellos. Se pretende confirmar que la alternancia de sentimientos que las diversas voces generan constituye la clave de lectura del texto, con el que Germán aspira a promover el fortalecimiento de una verdad de la fe cristiana y una esperanzada adhesión a la misma en aquellos a quienes se dirige.
\end{abstract}

PALABRAS CLAVE: pena, alegría, homilética, Bizancio, narración

The connection of dialogues through feelings: reading key in Homily VIII of Germanos of Constantinople

\footnotetext{
Abstract

This article hopes to demonstrate that the topoi of sorrow and joy support the narrative structure of Homily VIII of Germanos of Constantinople. Along with the alternation of speeches that are interspersed with the main story, an alternation in the reactions they raise can also be identified. The organization of these speeches will be reviewed in relation to the main thread, and the response produced by each of them will be analyzed. The purpose is to confirm that the alternation of feelings that the various voices generate constitutes the key to reading the text, with which Germanos aspires to promote the
} 
strengthening of a truth of the Christian faith and a hopeful adherence to it in those to whom is adressed.

KEYWORDS: sorrow, joy, homilies, Byzantium, narrative

Las homilías pronunciadas en el siglo octavo por sacerdotes, obispos y patriarcas adoptaron una variedad de formas: homilías exegéticas, homilías catequéticas y mistagógicas, homilías ocasionales -dedicadas a conmemorar un evento en particular-, homilías socio-éticas, homilías polémicas, homilías festivas, panegíricos y $\dot{\varepsilon} \gamma \kappa \omega \mu \mathrm{L} \alpha$, catequesis monásticas, homilías teológicas. ${ }^{1}$ Los límites entre un tipo y otro suelen resultar flexibles, y así una homilía individual puede mostrar más de una forma y alternar entre un estilo más informal y otro más literario. De esos diferentes tipos, Germán utilizó varios de ellos. En este caso nos centraremos concretamente en aquellas que escribió sobre la Dormición de María, más precisamente la VIII, y su posible encuadre en algún tipo particular.

Las homilías festivas, escritas en honor de grandes fiestas de la Iglesia, pretenden tanto ofrecer alabanzas y honor como instruir. Muchas de ellas presentan una sección ética en la que el orador extrae una lección moral del tema tratado, antes del final doxológico. Las homilías teológicas, en tanto, tienen como propósito exponer doctrina cristiana, a veces en respuesta a desafíos externos o internos o en conexión con asociaciones litúrgicas.

Las de Germán que nos ocupan se encuadran claramente como homilías festivas, en tanto son pronunciadas en ocasión de la fiesta de la Dormición, pero con rasgos también de las homilías teológicas. Escritas en honor de la fiesta mariana de la Dormición, veremos cómo al mismo tiempo el autor transmite y reafirma cuestiones fundamentales vinculadas con la doctrina teológica que había sido objeto de controversia en los siglos anteriores.

Durante el siglo séptimo ${ }^{2}$ se produce el surgimiento de numerosas fiestas litúrgicas, la mayoría de ellas vinculadas con la Virgen: Dormición, Natividad, Concepción de Ana. Paralelamente, se multiplican también entre los grandes predicadores de esa época, las homilías referidas a esas fiestas.

Esas homilías presentan una particularidad que no aparece ni antes ni después: se agrupan de a dos, tres o incluso cuatro. Así por ejemplo, sobre la Dormición de María encontramos tres homilías de Germán de Constantinopla, tres de Andrés de Creta, tres de Juan Damasceno.

En el caso de Germán, Chevallier (1937) la llama 'trilogía incompleta'. Efectivamente diversos autores han considerado que las dos primeras eran en realidad una sola, que fueron luego separadas de acuerdo al esquema de Juan Damasceno.

2 Cfr. al respecto Cunningham (2011:92) y Chevallier (1937:361-367), quien a partir de los detalles que surgen de la lectura de las homilías de Juan Damasceno, concluye que estas fueron pronunciadas la misma noche y ante el mismo público, formando una trilogía Muchos autores coinciden en que ambas conformaban una única Homilía, luego 'fraccionada' de acuerdo con el esquema de las Homilías sobre el mismo tema de Andrés de Creta y Juan Damasceno, o para adecuarse al esquema de tres homilías que se leerían en las fiestas de la Virgen. 
Las cuestiones vinculadas con el final de la vida de la Virgen, que no está relatada en las Escrituras, fueron mucho tiempo objeto de discusión entre los cristianos. Entre los siglos V y VI aparece una proliferación de escritos que refieren la partida de María, los cuales parecen provenir de diversas tradiciones. En muchas de ellas el cuerpo y el alma de María solo se separan temporalmente, usualmente por tres o cuatro días, ${ }^{3}$ después de lo cual su cuerpo es llevado al cielo; son las que Shoemaker (2002:3) llama tradiciones 'asuncionistas, porque se corresponden con el dogma moderno de la Asunción de la Virgen. En otras narraciones, en cambio, no aparece la resurrección del cuerpo; se trata de las tradiciones 'no asuncionistas'. Lo que unifica a todas las tradiciones es el modo

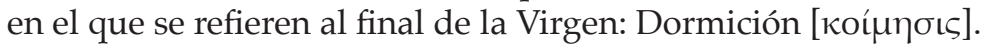

En tiempos de Germán, Patriarca de Constantinopla, que vivió aproximadamente entre los años 640 y 730, la fiesta de la Dormición, según dijimos, ya se había consolidado. En las últimas décadas del siglo VI el emperador Mauricio había restaurado la basílica de Getsemaní, sitio considerado en aquel momento como el de la tumba de la Virgen, y había establecido la celebración litúrgica de su paso a la gloria como fiesta para todo el imperio.

Daley (2001:72-75) atribuye a dos razones fundamentales el crecimiento de la devoción a la Virgen y la instauración definitiva de la fiesta de su partida. Por un lado, explica, la veneración a María y el énfasis puesto en su participación en la historia de la salvación seguramente fueron consecuencia de las discusiones de siglos anteriores en torno a la persona de Cristo, de la fuerte afirmación de su divinidad y del efecto transformador que esta tuvo en su propia naturaleza humana y en la de los que fueron cercanos a Él, la Virgen de un modo especial. ${ }^{4}$ Al mostrarse semejante a su Hijo y multiplicarse sus privilegios, aparece como una mediadora más accesible para los fieles cristianos. Por el otro, el autor hace hincapié en una preocupación diferente, más estrictamente escatológica, que es la de responder a una fuerte ansiedad ante la muerte que aparentemente empezó a extenderse entre los cristianos, a la incertidumbre sobre lo que venía después, al temor frente al juicio y los posibles castigos.

Germán se habría basado fundamentalmente en el apócrifo Transitus Mariae y en una Dormición escrita por Juan de Tesalónica para escribir esas homilías sobre el tema, que se ubican claramente como 'asuncionistas'. Las dos primeras $^{5}$ constituyen una reflexión teológica sobre el acontecimiento y en ellas se pueden identificar dos de los dogmas ${ }^{6}$ que sirvieron luego de base para establecer el de la Asunción: en tanto no había evidencia histórica del acontecimiento, el dogma debió ser proclamado sobre la base de otros ya establecidos, que implicaban que la Virgen no murió realmente, sino que permaneció inmortal: son los de la Maternidad Divina de María y su Virginidad Perpetua. ${ }^{7}$ De ellos nuestro autor desprende, como otros Padres de su tiempo, la afirmación de la Dormición. La tercera homilía (PG 360A-372D), que en esta oportunidad nos ocupa, es la única de carácter propiamente narrativo.

3 En el caso de Germán, por apenas un momento.

4 Cfr. al respecto Daley (2002:72).

5 Muchos autores -junto a Chevallier, arriba mencionado-, consideran que ambas conformaban una única Homilía, luego 'fraccionada' de acuerdo con el esquema de las Homilías sobre el mismo tema de Andrés de Creta y Juan Damasceno, o para adecuarse al esquema de tres homilías que se leerían en las fiestas de la Virgen.

6 Establecidos como tales en tiempos de Germán.

7 A esto la Iglesia Occidental agregaría más tarde los dogmas de la Inmaculada Concepción y del Pecado Original, que juntos sugerían la inmortalidad de María. Cfr. al respecto Shoemaker (2002:15-16). 
La Homilía comienza con una Introducción (360A-360B), en la que Germán

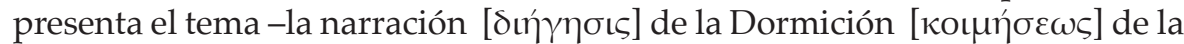

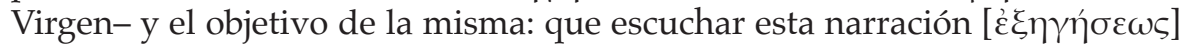

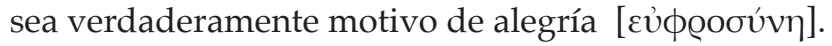

A continuación da inicio a la narración principal (360B-360C). Germán relata que un ángel fue enviado a María ${ }^{8}$ para comunicarle su próximo paso a los cielos. Sin embargo no aparece lo que dice el ángel, sino que inmediatamente es el propio Cristo quien toma la voz en el relato (360C-364B), y le habla directamente a su Madre: recuerda el momento de la Anunciación, se refiere a su rol de protectora de los hombres, de mediadora y puente entre la muerte y la vida; finalmente le anuncia su Dormición y lo que esta representará para ella, y le da detalles del momento: debe tenderse en el sepulcro de Getsemaní -en ese marco evoca su propia Pasión-, e inmediatamente será trasladada a los cielos; llegarán los apóstoles, que serán los encargados de realizar las honras fúnebres.

Luego se retoma la narración principal, siempre en boca de Germán (364B-365B), en la que se refiere cómo María prepara los detalles de su partida. El hilo narrativo es interrumpido por las palabras que la Virgen dirige a las mujeres que la acompañan, explicándoles lo que este momento supone para ella (365A).

A continuación llegan los Apóstoles -por los aires, entre nubes y truenos-, y el diálogo de ellos con María ocupa la parte siguiente del relato (365B-365D). Los discípulos expresan lo que la Virgen ha significado para cada uno todo este tiempo -la presencia de Cristo entre ellos-, y anuncian su futura partida. A ello María responde consolándolos y dando indicaciones sobre su entierro: deben llevar su cuerpo al sepulcro y ser ellos quienes realicen sus exequias.

Germán refiere a continuación (365D-368A) la llegada de Pablo, la manera en la que es recibido y cómo los demás apóstoles le cuentan para qué ha venido.

Pablo toma la palabra entonces, y tras alabar a la Virgen, expresa cómo, al igual que el resto de los Apóstoles, en ella veía a Cristo, al que nunca vio corporalmente. Y afirma que, así como hasta ahora había predicado que de ella nació Dios, en adelante va a enseñar que ella se ha ido junto a Él, para que todos sepan que cuentan con ella como intercesora.

Germán retoma entonces la narración (368B-369C) para referir de modo sencillo y preciso el momento de la Dormición: la Virgen se despide, se tiende sobre el lecho que había preparado y entrega su espíritu 'como en un sueño'. Pedro entonces eleva una plegaria y los demás Apóstoles llevan el cuerpo al sepulcro. Una multitud los acompaña, impactada por la inesperada partida de María y asombrada por la llegada de los Apóstoles, que es nuevamente relatada. Un judío al querer tocarla pierde sus manos, que le son devueltas por intervención de Pedro. Pedro y Pablo colocan el cadáver en el sepulcro, y en ese momento el cuerpo es arrebatado de la sábana con la que lo sostenían, pero no se ve quién se la lleva. Nadie duda de que es el propio Cristo.

Los Apóstoles toman la palabra ahora (369C-372B) y hablan a la muchedumbre: refuerzan lo que acaba de ocurrir -repiten cómo María, después de morir, 
fue tomada de sus manos y llevada a lo alto-; ordenan a quienes los escuchan que transmitan esto a los demás, para que ellos también crean; nuevamente insisten en que María fue llevada al cielo antes de que fuera puesta la piedra del sepulcro. Germán cierra entonces la narración (372B-372D) refiriéndose esta

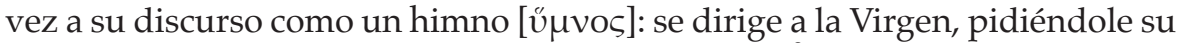
intercesión, y termina con una oración de alabanza. ${ }^{9}$

En esta homilía, el autor, en su intento de convencer por el discurso a su audiencia, utiliza variados recursos retóricos. Uno de los más abundantes es el de la repetición/anáfora, del cual ofrecemos algunos ejemplos:

Cuando Jesús le habla a su Madre, anticipándole su Dormición, se esfuerza por transmitirle tranquilidad al respecto; en la reiteración anafórica del verbo parece subrayarse la fuerza de la promesa, y da la impresión de que Germán, con su homilía, está intentando transmitir a quienes lo escuchan la misma confianza que Cristo a la Virgen:

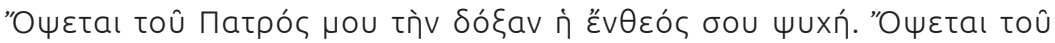

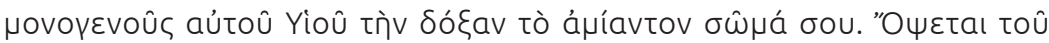

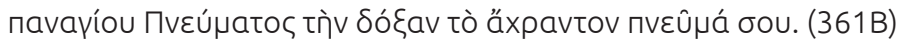

Verá la gloria de mi Padre tu alma inspirada en Dios. Verá la gloria de su Hijo unigénito tu cuerpo sin mancha. Verá la gloria del Espíritu Santo tu espíritu puro.

En el mismo discurso, la repetición del pronombre 'E $\gamma \omega$ parece reforzar el poder de Cristo en tanto Dios, que se encarnó en una mujer virgen, que promete hacerla feliz, glorificarla ante el mundo y erigirla en mediadora entre los hombres y su Padre:

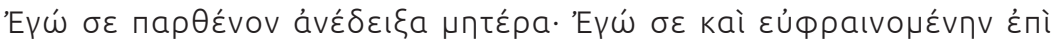

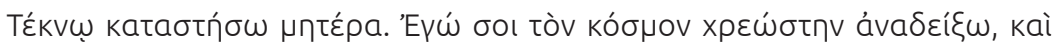

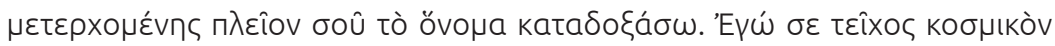

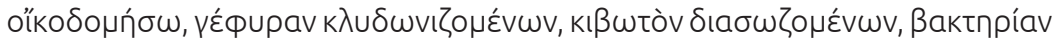

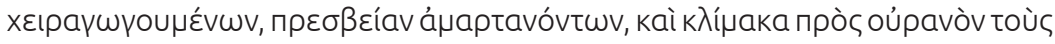

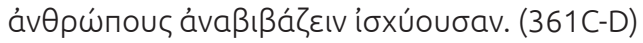

Yo te hice madre virginal; yo te haré también una madre que se regocija en su Hijo. Yo te mostraré al mundo que es tu deudor, y glorificaré tu nombre aún más a medida que seas trasladada. Yo te construiré como un muro para el mundo, un puente para los que están inundados, un arca para los que están siendo salvados, un bastón para los que están siendo guiados por la mano, una intercesión para los que están pecando, y un escalera que tiene el poder de elevar a la humanidad al cielo. ${ }^{10}$

La repetición de un término se ve en ocasiones reforzada por idénticas construcciones sintácticas que se repiten tras el mismo. Tal es el caso que sigue, por ejemplo,

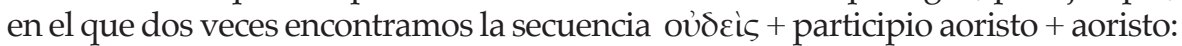

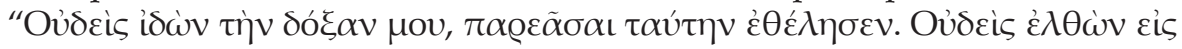

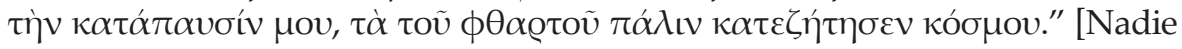

9 En esta doxología final llama la atención que solo se alaba a la Virgen, y no a la Trinidad, como era habitual. 10 La secuencia de imágenes que representan la intercesión de la Virgen operan también como una suerte de anáfora. 
habiendo visto mi gloria estuvo dispuesto a dejarla pasar. Nadie habiendo entrado en mi descanso buscó nuevamente el mundo perecedero] (361A).

Otro recurso muy utilizado por Germán en la Homilía es la antítesis. También en las palabras de Cristo a María aparece el contraste entre la humanidad de la Virgen, simbolizada en su cuerpo, y la divinidad de su Hijo: "E

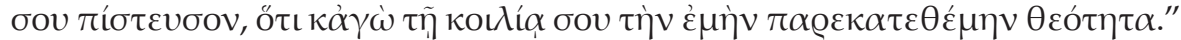
[Confíame tu cuerpo, porque también deposité mi divinidad en tu vientre] (361B). En estas líneas, además del contraste que representa la divinidad de Cristo encerrada en el vientre humano de su madre, aparecen puestos en relación el rol de la Virgen en el nacimiento de Cristo con el rol de Cristo en la muerte de la Virgen; ambos son presentados como un acto de confianza del uno en el otro, y la imagen cobra aún más fuerza.

Algo similar encontramos en otros pasajes, en los que se enlazan también los momentos de la Encarnación y de la Dormición, de la vida y de la muerte:

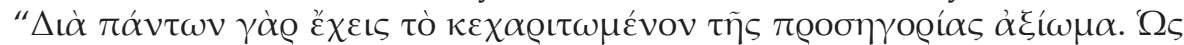

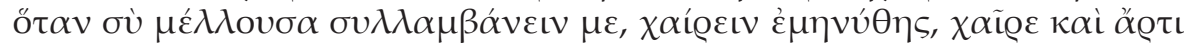

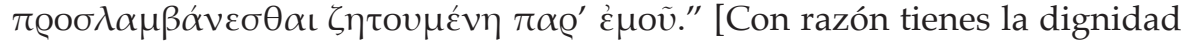
del título de 'llena de gracia' en todos los sentidos. Como cuando tú estabas a punto de concebirme, recibiste un anuncio de gozo, alégrate también ahora

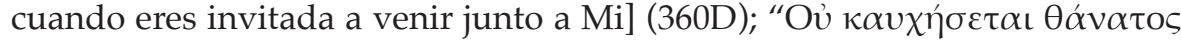

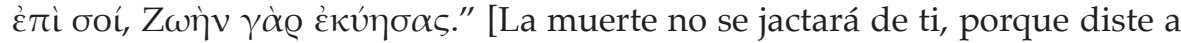
luz a la Vida] (361C).

Otros muchos ejemplos son representativos del contraste que, como veremos más adelante, es el que estructura toda la homilía:

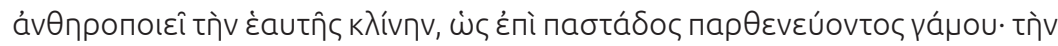

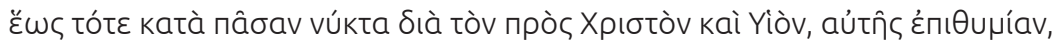

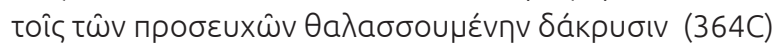

adorna su cama con flores, como la cámara del matrimonio de una virgen; la cama hasta entonces todas las noches (debido a su deseo por su Cristo e Hijo) inundada por las lágrimas de sus oraciones.

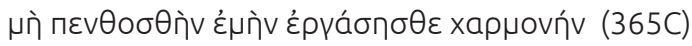

no transformen en pena mi regocijo

En el primero de los textos, la cama revestida con flores contrasta con la cama bañada en lágrimas, en una imagen más visual; en el segundo, en el pedido que la Virgen dirige a los apóstoles, la antítesis se vuelve explícita por los propios términos utilizados.

En otras ocasiones, la oposición es tan fuerte que se transforma en oxímoron. Tal es el caso que aparece en el Prólogo, cuando Germán anuncia el tema

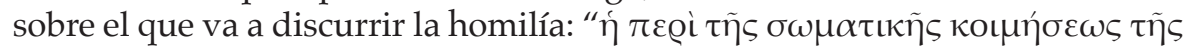

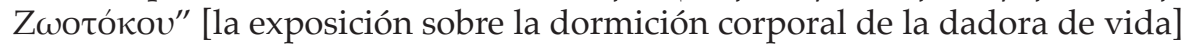
(360A), o en diversas expresiones referidas a la Encarnación de Dios, en algunas de las cuales paradojalmente se unen las imágenes de Dios Hijo -encarnado y nacido de una mujer-, y Dios Padre y Creador de esa misma mujer: " $\tau \eta \nu$ $\sigma \tilde{\omega} \mu \alpha \tau \tilde{\omega} \dot{\alpha} \sigma \omega \mu \alpha \dot{\alpha} \tau \omega \chi \chi 0 \emptyset \gamma \eta \dot{\sigma} \sigma \alpha \sigma \alpha v^{\prime \prime}$ [tú que proveíste un cuerpo al sin cuerpo]

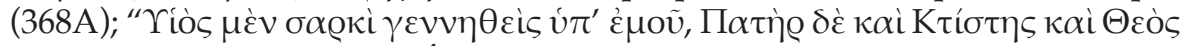

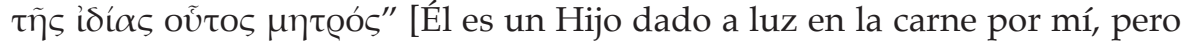


Padre y Creador y Dios de su propia madre] (365A); “ $\tau \tilde{\omega}$ Xอı $\tau \tilde{\omega} \kappa \alpha \grave{i} \Theta \varepsilon \tilde{\omega} \kappa \alpha \grave{i}$ $\sigma \omega \mu \alpha \tau \iota \kappa \tilde{\omega} \alpha \dot{v} \tau \tilde{\eta} \varsigma \Upsilon \hat{\imath}\left(\tilde{\omega}^{\prime \prime}\right.$ [Cristo Dios y su Hijo corpóreo] (368D).

Pero sin duda el gran recurso que en esta Homilía utiliza Germán para transmitir con más fuerza su mensaje y volverlo más efectivo, es el de los diálogos. ${ }^{11}$ En una homilía estructurada sobre el encadenamiento de diversos diálogos, resulta signficativo profundizar en las funciones retóricas a las que estos responden.

Como se puede apreciar al considerar el contenido de la Homilía hay un hilo narrativo principal, el que aparece en boca del propio Germán, que va siendo interrumpido/enriquecido por otras voces, centradas siempre en lo mismo, la Dormición. ${ }^{12}$ La historia va siendo contada por los propios personajes: Cristo, María, los Apóstoles. Toda la homilía es un traer y volver a traer frente al presente del espectador el pasado de la Dormición de la Virgen, estableciéndose una relación sumamente dinámica entre el narrador y el narratario. Se pierde la impresión de estar escuchando un relato, porque la recurrente presencia de los diálogos transmite la sensación de algo que está ocurriendo frente a los propios ojos. Se advierte entonces un relato repetitivo, ya que se cuenta varias veces lo ocurrido una vez. Pero las voces son diversas, y la focalización interna, múltiple: el acontecimiento narrado varias veces es el mismo, pero por diferentes personajes que lo hacen desde diferentes perspectivas.

El relato de Germán, desde el comienzo al fin, es de algo que ya pasó; sin embargo, en la utilización de los tiempos verbales se nota una diferencia: al referir el momento preciso de la 'Dormición' lo hace en presente, y así la sensación de realidad de lo que está relatando -un hecho que en realidad no aparece en las Escrituras-, cobra particular fuerza; cuando se refiere en cambio a la 'Asunción' sí lo hace en pasado, afirmando la certeza de algo

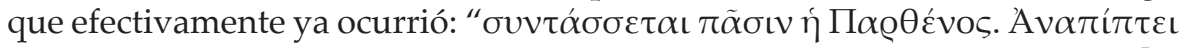

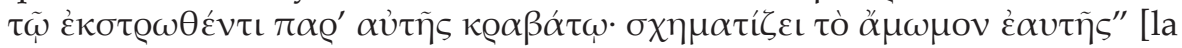
Virgen se despide de todos. Se reclina en el catre que se ha extendido; arregla

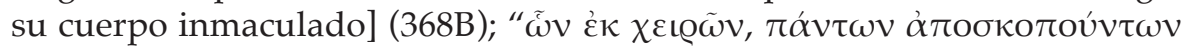

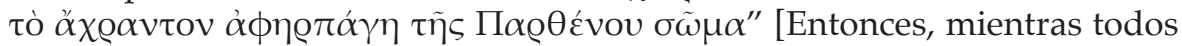
miraban, el cuerpo puro de la Virgen fue arrebatado de sus manos] (369B).

Cristo retoma el mismo relato de un modo 'anticipatorio': al hablarle a su Madre, le adelanta los acontecimientos que van a ocurrir. Aparecen por tanto los verbos en futuro, entremezclándose con otros en imperativo -con los que el Hijo anima a María a dar ese paso con serenidad y le da indicaciones sobre lo que debe hacer-, y algunos en aoristo, ya que evoca también el momento de la Pasión: ${ }^{13}$

Coloca [Өغ̀c] tu cuerpo en el lugar de Getsemaní con buen ánimo, como Yo,

11 Cunningham (2013:103) señala tres funciones básicas del diálogo en las homilías: la retórica, la teológica o exegética y la que podríamos denominar 'histórica'. En este artículo solo nos referiremos a la retórica, pero sin duda la exegética tiene también para Germán un valor fundamental, ya que se sirve del diálogo para reforzar cuestiones significativas de la doctrina cristiana, con sus permanentes alusiones a la Encarnación o a la divinidad de Cristo, entre otras.

12 Messis; Mullet; Nilsson (2018:3-4) señalan dos características de la narrativa bizantina que pueden de alguna manera apreciarse en esta Homilía: que a menudo se construye a partir de diversas narraciones que sirven de exempla y constituyen unidades independientes, y que se multiplican las referencias bíblicas "que ejemplifican, explican o incluso resumen y reemplazan la narración, una narración que a menudo revela su significado real sólo después de una comprensión acabada de las referencias que contiene" (traducción propia).

13 Sirvan estas líneas solo como ejemplo de un largo pasaje que evoca otros momentos de la vida de Cristo y su Madre y en el que aparecen las mencionadas formas verbales. 


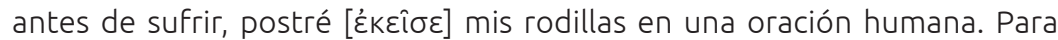
prefigurar tu dormición, yo también doblé [žk $\lambda$ ıva] las rodillas de mi cuerpo en ese lugar. Así como Yo, después de arrodillarme en ese momento, pasé

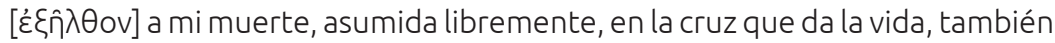
tú después de la caída de tus restos serás inmediatamente transferida

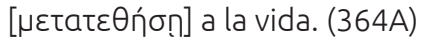

El hecho de que tan al comienzo de la Homilía aparezca en boca de Cristo lo que va a ocurrir sin duda no es casual: le sirve a Germán para dar autoridad a un tema largamente controvertido. En sus palabras aparecen cuestiones fundamentales para los fieles cristianos en general, y se enfatiza la atemporalidad del mensaje que se quiere transmitir: la Encarnación, la Virginidad de María, su Dormición y la posibilidad de la vida después de la muerte, que se extiende a toda la humanidad.

Las distintas intervenciones de María, así como su modo de reaccionar ante las palabras de Cristo, constituyen un claro ejemplo del valor de los diálogos para profundizar en los caracteres de los personajes. Todas ellas tienen el mismo tono, y son expresión de su serenidad y gozo ante la Dormición, que le significará volver a estar junto a su Hijo, y de consuelo a quienes quedan, los apóstoles o las mujeres, que temen quedar 'huérfanos'. En ellas son retomados también algunos de los detalles de lo que va a ocurrir.

En los discursos de los Apóstoles aparecen referencias a los hechos de la Dormición de dos maneras: de modo anticipatorio, adelantando lo que está por acontecer, en sus primeras intervenciones; repitiendo lo ya acontecido, dos veces en su intervención del final. En este caso las referencias están en aoristo:

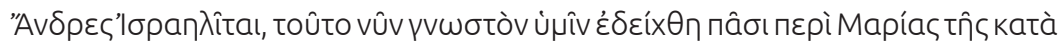

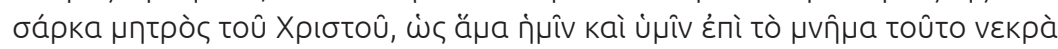

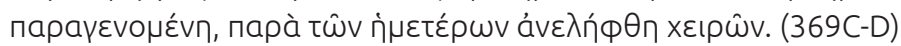

Hombres de Israel, esto se les ha dado a conocer ahora a todos ustedes acerca de María, la madre de Cristo según la carne, a nosotros y a ustedes juntos que habiendo llegado muerta a esta tumba, fue arrebatada de nuestras manos.

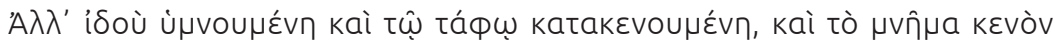

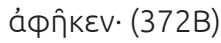

Pero he aquí que, mientras estaba siendo honrada con himnos y llevada en procesión a la tumba, dejó vacío el sepulcro.

En resumen, en relación con la historia en sí misma, podemos decir que el mismo momento es relatado al menos tres veces: es anticipado por Cristo y por los Apóstoles, contado por Germán y 're-contado' por los Apóstoles, lo cual destaca la importancia del hecho narratológico, centro de la homilía.

Sin duda este sermón del Patriarca de Constantinopla es un buen ejemplo de la importancia del diálogo como elemento nuclear en la homilética bizantina. ${ }^{14}$ Está construido prácticamente sobre una secuencia de diálogos, que ocupan la mayor parte del relato. Todos ellos son intratextuales, e inventados por el predicador entre diversos personajes bíblicos. Al no tratarse de un hecho que 
esté registrado en la Escritura, Germán encuentra en el diálogo el mejor modo de transmitir lo que el mismo ha recibido de la tradición, y así pone en boca de esos personajes aquello que quiere transmitir a quienes lo escuchan. No cita las palabras que ellos habrían dicho: los pone directamente frente a su audiencia. ${ }^{15}$

Vale la pena recordar también que el término griego ó $\mu$ íí significa 'conversación', y partimos por tanto del supuesto de que el predicador desde un comienzo está interactuando con su audiencia. $Y$ es justamente al principio, en el prólogo, donde podemos encontrar algunas expresiones de carácter extratextual, ${ }^{16}$ de las que el narrador se sirve para captar la atención de sus oyentes e involucrarlos en la historia. Así, al final del prólogo y antes de iniciar el relato, Germán invita suavemente -en primera persona plural del subjuntivo

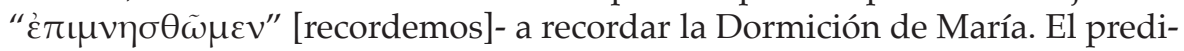
cador se erige así como una suerte de mediador entre los hechos narrados y su congregación, produciendo un mayor acercamiento.

Nuestro autor, en la utilización de los diálogos intratextuales y en sus acotadas expresiones extratextuales, se inserta en un hábito propio de la homilética bizantina del siglo VIII. Lo que resulta particularmente llamativo, y propio de Germán, es el modo en el que los diferentes diálogos se enlazan, algo que es posible advertir en las reacciones que los personajes van experimentando:

(1) el discurso de Cristo, que sigue casi inmediatamente al propósito de la Homilía formulado por Germán, está inundado de términos vinculados con la alegría:

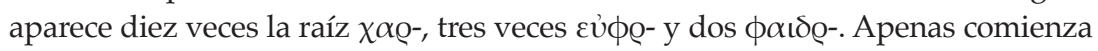
a hablar, encontramos las primeras menciones, que luego se multiplican:

(360C) Es hora, dice el Señor, de traerte madre mía [hacia mí. Así como llenaste de alegría [xapâc] la tierra y a los que están en la tierra, oh llena de gracia

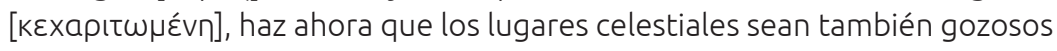

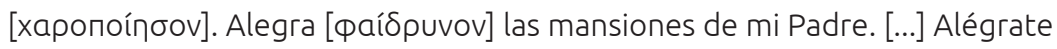
[xaîpe] incluso ahora, como también antes. Con razón tienes la dignidad del

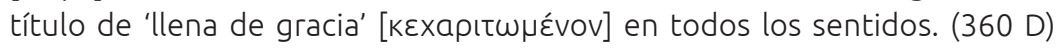
Como cuando estabas a punto de concebirme, recibiste un anuncio de gozo

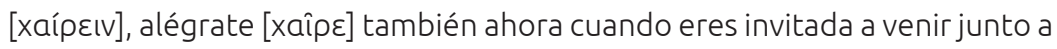

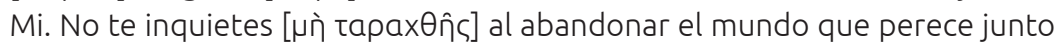
con sus deseos. [...] (361A) Tú te diriges a una vida más viva, a un descanso de alegría [xapâc], a una paz indestructible, a una vida sin preocupaciones [...] Porque donde estoy, hay vida eterna, alegría [xapá] incomparable [...] Donde está Dios, toda bondad, todo deleite, toda dicha [థaı́рótnৎ] [...] (361C) Ven de buen grado hacia el que ha nacido de Ti. Quiero regocijarte [عú申pâvai] como debería un hijo. [...] Yo te hice madre virginal; yo te haré también una

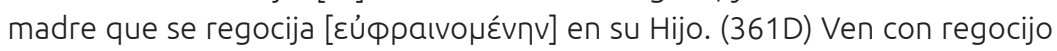

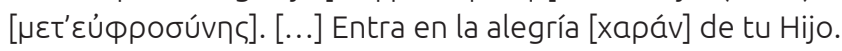

(2) la reacción de la Virgen a las palabras de su Hijo es de alegría: "Habiendo escucha-

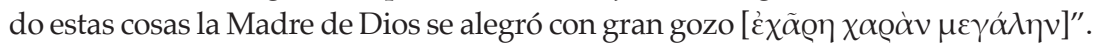
(364B)

15 Cunningham (2013:112-113) se pregunta acertadamente cómo habría pronunciado un predicador estos diálogos, si habría adoptado diferentes tonos de voz o gestos al hablar por boca de los personajes; y supone que es probable que varios clérigos hayan intervenido en la pronunciación de los mismos. 
(3) las mujeres que acompañan a la Virgen (365A), cuando se enteran de lo que va a

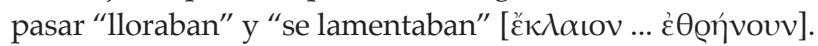

(4) pero ella les responde (365B) que ante la perspectiva de reunirse con su Hijo, no

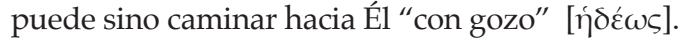

(5) los Apóstoles, por su parte, experimentan sentimientos encontrados (365C): cuando la Virgen les cuenta que se aproxima su Dormición, expresan su alegría

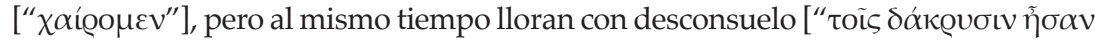
$\dot{\alpha} \pi \alpha \varrho \alpha \mu u ́ \theta \eta \tau о \iota "]$.

(6) al verlos María (365C-365D) los exhorta a alegrarse [“ $\chi \alpha$ í́ع $\tau \varepsilon^{\prime \prime}$, a no conver-

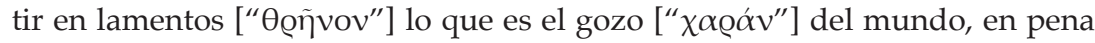

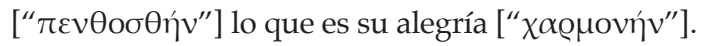

(7) en cuanto a Pablo (368B), sus reacciones son las mismas que las de los demás Apóstoles, pero manifestadas en orden inverso: llora primero (" $\mu \varepsilon \gamma \alpha \dot{\lambda} \omega \kappa \alpha \dot{\mathrm{i}} \dot{\varepsilon} v \delta \alpha \kappa \rho v ́ \omega$ $\left.\sigma \tau \varepsilon v \alpha \gamma \mu \tilde{\omega} \tilde{c}^{\prime}\right)$ al saber lo que va a ocurrir, mas luego manifiesta su dicha (" $\chi \alpha \tilde{\mathrm{i}} \varrho \varepsilon$

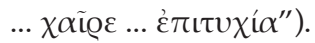

El encadenamiento de los diversos discursos se da, según acabamos de ver, a través de los topoi de la tristeza ${ }^{17}$ y de la alegría, que proporcionan el esquema de lectura del texto, en clara relación con el objetivo con el que fue escrito, explicitado por Germán al comienzo: que la narración sería motivo de alegría. A través de ellos, en la escucha repetida de los términos que los evocan, en la proximidad con las situaciones de los personajes que los experimentan, Germán no sólo transmite teología, hace que pueda ser vivenciada.

Los topoi de la pena y de la alegría son evangélicos, y tienen un claro paralelo con la historia de Jesús - de hecho las alusiones a la Pasión y a la Resurrección son recurrentes en la Homilía-, pero Germán usa la alternancia de los discursos para darles mayor fuerza y promover en quienes lo escuchan una experiencia semejante. Esa misma alegría experimentada por los personajes del relato de la Dormición, también será vivida por los fieles que lo escuchan, en la certeza de que cuentan con la Virgen como intercesora y abogada ante el Señor, y de que la vida sigue tras la muerte corporal, de que ellos también pueden 'ganarle' a la muerte, como María lo hizo.

Si bien cuando Germán escribe, como decíamos al principio, la Dormición de la Virgen ya no era un tema en discusión, ${ }^{18}$ él parece retomar aquella doble preocupación de los siglos previos, a la que los escritores cristianos anteriores ya habían intentado dar respuesta, y en esta Homilía profundiza tanto en el rol de mediadora de María -en el que no nos hemos detenido-, como en la certeza de su vida feliz junto a su Hijo.

Hacia esa certeza es hacia lo que el Patriarca va dirigiendo el discurso, al estructurarlo en torno a la experiencia de los sentimientos que va presentando. Pretende así, creemos, contrarrestar posibles miedos, transmitir consuelo y esperanza al discurrir sobre un tema tratado por muchos, pero desde una perspectiva original tanto en cuanto al énfasis que pone en los topoi mencionados como en cuanto al modo en que se sirve de ellos en su narración. Esa manera particular de utilizarlos, como 'enlace' de los diversos discursos, vivenciados por los personajes del Evangelio, facilita y refuerza la transmisión del contenido que quiere transmitir.

17 Pero la tristeza siempre se apacigua ante la intervención de algún otro personaje.

18 Las controversias se centraban más bien en la cuestión de las voluntades de Cristo. Germán, una vez nombrado obispo, convocó a un sínodo que oficialmente restableció la fe católica y condenó a los monotelitas, que afirmaban una única voluntad en Cristo en contra de los establecidos por los Concilios anteriores. 
Al presentar a sus oyentes los contenidos sagrados vinculados con la Dormición no simplemente mediante un relato, sino encarnados en personajes concretos que hablan, sienten y se conmueven, facilita que su audiencia pueda participar también de aquellos.

Germán logra así mediante los diálogos atravesados por los topoi de la alegría y el dolor, acercar a su audiencia de una manera más cercana y comprensible el mensaje teológico de la Dormición de la Virgen y cuanto se vincula a ella: la humanidad de la Virgen, el misterio de la Encarnación y de la Resurrección de Cristo. 


\section{Q Bibliografía}

"Cunningham, M. (2008). "Homilies". En: Jeffreys, E.; Haldon, J.; Cormack, R. (eds.) The Oxford Handbook of Byzantine Studies. Oxford: Oxford University Press, 872-882.

" Cunningham, M. (2011). "Messages in Context: The Reading of Sermons in Byzantine Churches and Monasteries". En: Lymberopoulou, A. (ed.). Byzantium: Visions, Messages and Meanings. Festschrift for Prof Leslie Brubaker on her 60th Birthday, Ashgate, 83-98.

" Cunningham, M. (2013). "Dramatic device or didactic tool? The function of dialogue in Byzantine preaching". En: Jeffreys E. (ed.). Rhetoric in Byzantium. Papers from the Thirty-fifth Spring Symposium of Byzantine Studies. London, New York, Routledge: 101-113.

»Chevalier, C. (1937). "Les trilogies homilétiques dans l'élaboration des fêtes Mariales, 650-850", Gregorianum 18, 361-378.

»Daley, B. J. (1998). On the Dormition of Mary: Early Patristic Homilies. Crestwood: St. Vladimir's Seminary Press.

"Daley, B. J. (2001). "'At the Hour of Our Death: Mary's Dormition and Christian Dying in Late Patristic and Early Byzantine Literature", DOP, 71-89.

"Messis, Ch.; Mullett, M.; Nilsson, I. (eds.) (2018). Storytelling in Byzantium. Narratological approaches to Byzantine texts and images. Uppsala: Uppsala Universitet.

» Migne, J.P. (1857-1866). Patrologiae cursus completus. Series graeca. Paris: Garnier.

» Pons Pons, G. (trad.) (1990). Germán de Constantinopla. Homilias mariológicas. Madrid: Ciudad Nueva.

» Roth, G. E. (2011). Paradox Beyond Nature: the Marian Homilies of Germanos I, Patriarch of Constantinople (715-730). Dayton: University of Dayton.

» Shoemaker, S. (2002). The Ancient Traditions of the Virgin Mary's Dormition and Assumption. Oxford: Oxford University Press. 